University of Louisville

ThinkIR: The University of Louisville's Institutional Repository

Faculty Scholarship

$5-2005$

\title{
Using a 0-10 Scale for Assessment of Anxiety in Patients with Acute Myocardial Infarction
}

\author{
Maria J. De Jong \\ Kyungeh An \\ Sharon McKinley \\ Bonnie J. Garvin \\ Lynne A. Hall \\ University of Louisville, lynne.hall@louisville.edu \\ See next page for additional authors \\ Follow this and additional works at: https://ir.library.louisville.edu/faculty \\ Part of the Critical Care Nursing Commons
}

\section{Original Publication Information}

De Jong, Maj Marla J. USAF, MS, CCNS, CCRN, CEN, RN; An, Kyungeh PhD, RN; McKinley, Sharon PhD, RN; Garvin, Bonnie J. PhD, RN; Hall, Lynne A. DrPH, RN; Moser, Debra K. DNSc, FAAN, RN Using a 0-10 Scale for Assessment of Anxiety in Patients With Acute Myocardial Infarction, Dimensions of Critical Care Nursing: May 2005 - Volume 24 - Issue 3 - p 139-146.

\section{ThinkIR Citation}

De Jong, Maria J.; An, Kyungeh; McKinley, Sharon; Garvin, Bonnie J.; Hall, Lynne A.; and Moser, Debra K., "Using a 0-10 Scale for Assessment of Anxiety in Patients with Acute Myocardial Infarction" (2005).

Faculty Scholarship. 691.

https://ir.library.louisville.edu/faculty/691

This Article is brought to you for free and open access by ThinkIR: The University of Louisville's Institutional Repository. It has been accepted for inclusion in Faculty Scholarship by an authorized administrator of ThinkIR: The University of Louisville's Institutional Repository. For more information, please contact thinkir@louisville.edu. 


\section{Authors}

Maria J. De Jong, Kyungeh An, Sharon McKinley, Bonnie J. Garvin, Lynne A. Hall, and Debra K. Moser 
Public reporting burden for this collection of information is estimated to average 1 hour per response, including the time for reviewing instructions, searching existing data sources, gathering and maintaining the data needed, and completing and reviewing the collection of information. Send comments regarding this burden estimate or any other aspect of this collection of information, including suggestions for reducing this burden, to Washington Headquarters Services, Directorate for information Operations and Reports, 1215 Jefferson Davis Highway, Suite 1204, Arlington, VA 22202-4302, and to the Office of Management and Budget, Paperwork Reduction Project (0704-0188), Washington, DC 20503.

\begin{tabular}{l|l} 
1. AGENCY USE ONLY (Leave blank) & 2. REPORT DATE
\end{tabular} 14.Jul.04 3. REPORT TYPE AND DATES COVERED

4. TITLE AND SUBTITLE

MAJOR REPORT

USING A 0-10 SCALE FOR ASSESSMENT OF ANXIETY IN PATIENTS WITH ACUTE MYOCARDIAL INFARCTION

6. AUTHOR(S)

MAJ DEJONG MARLA J

5. FUNDING NUMBERS

7. PERFORMING ORGANIZATION NAME(S) AND ADDRESS(ES)

UNIVERSITY OF KENTUCKY LEXINGTON

9. SPONSORING/MONITORING AGENCY NAME(S) AND ADDRESS(ES)

THE DEPARTMENT OF THE AIR FORCE

8. PERFORMING ORGANIZATION REPORT NUMBER

CI04-417

AFIT/CIA, BLDG 125

2950 P STREET

WPAFB OH 45433

\section{SUPPLEMENTARY NOTES}

12a. DISTRIBUTION AVAILABILITY STATEMENT

Unlimited distribution

In Accordance With AFI 35-205/AFIT SUPETPIBUTION STATEMEMT A Approved for Public Release Distribution Unlimited

13. ABSTRACT (Maximum 200 words)

\section{9}




\section{Title Page}

Title: Using a 0-10 Scale for Assessment of Anxiety in Patients with Acute Myocardial Infarction

\section{Authors:}

- Marla J. De Jong, RN, MS, CCNS, CCRN, CEN, Major

$\mathrm{PhD}$ Student

University of Kentucky, College of Nursing / United States Air Force

Lexington, $\mathrm{KY}$

- Kyungeh An, RN, PhD

Head Researcher

Seoul National University, College of Nursing

Seoul, South Korea

- Sharon McKinley, RN, PhD

Professor of Critical Care Nursing

University of Technology, Sydney

Sydney, Australia

- Bonnie J. Garvin, RN, PhD

Professor

Ohio State University, College of Nursing

Columbus, $\mathrm{OH}$

- Lynne A. Hall, RN, DrPH

Marcia A. Dake Professor of Nursing Science; Assistant Dean for Research and the $\mathrm{PhD}$ Program

University of Kentucky

Lexington, $\mathrm{KY}$

- Debra K. Moser, RN, DNSc, FAAN

Professor and Gill Chair of Nursing

University of Kentucky, College of Nursing

Lexington, $\mathrm{KY}$

Contact Author: Marla J. De Jong

527 College of Nursing

University of Kentucky

Lexington, KY 40536

Telephone: (859) 323-6687

FAX: (859) 223-7265

E-mail: mdejong@aol.com 
Institution Where the Work Was Performed: The Ohio State University, College of Nursing, and University of Kentucky, College of Nursing

Disclaimer Statement: The opinions or assertions contained herein are the private views of the authors and are not to be construed as official or as reflecting the views of the Department of the Air Force or the Department of Defense. 
Using a 0-10 Scale for Assessment of Anxiety in Patients with Acute Myocardial Infarction Background: Patients with acute myocardial infarction (AMI) often experience anxiety, an emotion that predicts adverse physiologic outcomes. Critical care clinicians have not adopted an anxiety assessment instrument for widespread use, due in part to the unavailability of an easy-toadminister anxiety instrument that is not burdensome to either clinicians or critically ill patients. Objectives: To determine whether a single-item anxiety assessment instrument, the Anxiety Level Index (ALI), is a valid alternative to the State Anxiety Inventory (SAI) or the anxiety subscale of the Brief Symptom Inventory (BSI) in assessing state anxiety for patients with AMI. Methods: In this prospective multi-center study, 243 inpatients with AMI rated their anxiety using the SAI, the anxiety subscale of the BSI, and the ALI. Anxiety Level Index scores were compared to SAI and BSI anxiety subscale scores using Spearman's rho test and the BlandAltman method.

Results: There were moderate, positive correlations between the SAI and the ALI $(r=.52, P<$ $.001)$ and between the ALI and the anxiety subscale of the BSI $(r=.45, P<.001)$. However, the Bland-Altman method revealed a moderate bias between the ALI and the SAI and between the ALI and the anxiety subscale of the BSI. As anxiety scores increased, the level of disagreement became more pronounced in both comparisons.

Conclusions: Although ALI scores were moderately and significantly correlated with scores on the SAI and the BSI anxiety subscale, the results of the Bland-Altman method indicate a lack of construct validity of the single-item measure. The quest continues to construct a simple selfreport measure of anxiety that is appropriate for critically ill patients with AMI.

Key Words: Anxiety, myocardial infarction, nursing assessment 
Anxiety is an inherent human emotion and a common psychological response to acute myocardial infarction (AMI). In fact, 10-26\% of hospitalized persons with AMI are more anxious than persons who have been diagnosed with a psychiatric disorder (Crowe, Runions, Ebbesen, Oldridge, \& Streiner, 1996; Moser \& Dracup, 1996). Anxiety associated with AMI is not unique to the United States; patients throughout the world experience anxiety after AMI (De Jong et al., in press).

Anxiety associated with AMI can be a dangerous phenomenon. Moser and Dracup (1996) reported that patients with higher state anxiety after AMI had a 4.9 times higher incidence of inhospital ventricular fibrillation, ischemia, and reinfarction than patients with lower anxiety. High state anxiety has been shown to predict 3-month survival following AMI (Thomas, Friedmann, Wimbush, \& Schron, 1997). Similarly, Frasure-Smith and colleagues (1995) reported that high state anxiety predicted recurrent cardiac events during the first year after AMI. Finally, for patients with recent $\mathrm{AMI}$ and a left ventricular ejection fraction $\leq 50 \%$, elevated anxiety was associated with more frequent cardiac events and higher mortality 6-10 years after the acute event (Denollet \& Brutsaert, 1998).

Given the above findings, it is easy to find nursing literature that emphasizes the need for clinicians to assess, document, and manage anxiety in patients with AMI (Bucher, 1999; Casey, Morrissey, \& Nolan, 1998; Cunningham, Del Bene, \& Vaughan, 2000; Kim et al., 2000; Malan, 1992; Webb \& Riggin, 1994). What is missing, however, are specific guidelines for how clinicians should assess anxiety. Instead, recommendations for assessing anxiety are vague. For example, clinicians are instructed to "assess for verbal and nonverbal signs of anxiety and when level of anxiety changes..." (Martinez, 2004, p. 826), perform active listening, and encourage patients to verbalize their emotions (Casey et al., 1998). The assessment of anxiety after AMI is 
not standardized and no anxiety assessment tool has been recognized as the gold standard. Consequently, although reliable and valid anxiety instruments are available, clinicians often neither complete nor document a formal anxiety assessment. When nurses do assess anxiety, they do so using a subjective approach (O'Brien et al., 2001). For example, nurses documented that patients were anxious, restless, or shaky, but did not use objective measures to assess anxiety (O'Brien et al., 2001). Nurses also use tachycardia, tachypnea, elevated blood pressure, and increased diaphoresis as indicators of anxiety (Frazier et al., 2002b; Moser et al., 2003a). However, interpretation of altered physiologic parameters is difficult because many factors other than anxiety influence them (McKinley, Stein-Parbury, Chehelnabi, \& Lovas, 2004).

The Spielberger State Anxiety Index [SAI] (Spielberger, Gorsuch, Lushene, Vagg, \& Jacobs, 1983) and the anxiety subscale of the Brief Symptom Inventory [BSI] (Derogatis \& Melisaratos, 1983) are two valid and reliable anxiety instruments that investigators have used to assess anxiety in patients with AMI. Clinicians often perceive that such anxiety instruments are too lengthy (Benotsch, Lutgendorf, Watson, Fick, \& Lang, 2000; Boker, Brownell, \& Donen, 2002), burdensome to acutely ill patients (McKinley, Coote, \& Stein-Parbury, 2003), clinically irrelevant, and difficult to administer. O'Brien and associates (2001) reported that clinicians never used an objective instrument to assess anxiety for 101 patients with AMI. Although 45 of these patients' medical records contained a brief subjective anxiety assessment, there was no association between clinicians' assessment of their patients' anxiety and patients' assessment of their own anxiety. Furthermore, clinician assessments of the same patient during the same time period differed.

Others documented the need for a simple method of assessing anxiety in acutely ill patients (McKinley et al., 2004; O'Brien et al., 2001) and suggested that a single-item anxiety 
assessment instrument may be the solution (O'Brien et al., 2001). Clinicians who care for patients with AMI routinely assess chest pain using a 0 to 10 numeric rating pain scale. Advantages of this pain scale are that clinicians require minimal training regarding its use, it is time efficient, and cardiac patients are familiar with it. If clinicians had a straightforward 0 to 10 numeric anxiety scale, they might assess and document anxiety more consistently. Furthermore, a 0 to 10 anxiety scale could eliminate difficulties with translating currently available anxiety instruments to non-English languages. Accordingly, the purpose of this study was to determine whether a single-item numeric rating scale for anxiety, the Anxiety Level Index (ALI), is a valid alternative to the SAI or the anxiety subscale of the BSI in assessing state anxiety for patients with AMI.

Methods

Design

In this prospective multi-center study, we assessed the state anxiety level of patients with AMI using the SAI, the anxiety subscale of the BSI, and the ALI. Subsequently, we compared the ALI scores with the SAI and BSI scores. The anxiety assessment was completed within 48 hours of the patient's admission for AMI.

Sample and Setting

The study was conducted in the cardiac care units of three large urban university medical centers located in the Midwest of the United States. Adult male and female patients were invited to participate in the study if they met the following inclusion criteria: 1) diagnosis of AMI confirmed by elevated cardiac enzymes and typical ECG changes; 2) pain free and hemodynamically stable at the time of assessment; 3) free of cognitive impairment; 4) free of 
non-cardiac serious or life threatening co-morbidities; and 5) able to speak English. A total of 243 patients were enrolled.

Measurement

Sociodemographic and Clinical Data. Prior to the anxiety assessment, each patient provided his or her age, educational level, ethnicity, and marital status. Trained research assistants reviewed each patient's medical record to collect the following clinical data: peak cardiac enzyme levels, Killip classification, type of AMI, smoking status, and history of AMI, coronary artery bypass grafting, hypertension, and diabetes.

Anxiety. For purposes of this study, we measured state anxiety, which has been defined as a "transitory emotional state or condition of the human organism...that is characterized by subjective, consciously perceived feelings of tension and apprehension, and activation of the autonomic nervous system" (Spielberger, 1972, p. 39). Each patient completed three self-report instruments that reflect state anxiety: the SAI, the anxiety subscale of the BSI, and the ALI. The SAI is a 20 -item instrument that enables persons to rate their anxiety at the present time. For each item, respondents indicate their agreement using a scale of 1 ("not at all") to 4 ("very much so"); thus, total scores range from 20 or 80 . It takes 5-10 minutes to complete this instrument. The SAI has been used to assess anxiety in patients with AMI (Crowe et al., 1996; Frasure-Smith \& Lesperance, 2003; Frasure-Smith et al., 1995; Frazier et al., 2002a; Kim et al., 2000; O'Brien et al., 2001; Rose, Conn, \& Rodeman, 1994; Webb \& Riggin, 1994) and previous research has supported its reliability and validity (Spielberger et al., 1983). The Cronbach's $\alpha$ reliability coefficient for our sample was .93 . Normative values for healthy 50-69 year-old men, healthy 50-69 year-old women, medical-surgical patients, and general psychiatric patients are $34.51 \pm$ $10.34,32.20 \pm 8.67,42.38 \pm 13.79$, and $47.74 \pm 13.24$, respectively (Spielberger et al., 1983). 
The 6-item anxiety subscale of the BSI instrument includes brief descriptions of psychological symptoms that are associated with anxiety. Using a 0 ("not at all") to 4 ("extremely") scale, participants rate their level of distress concerning these symptoms. The six scores are totaled and averaged. The averaged score quantifies the patient's level of anxiety and can range from 0 to 4 . Like the other two instruments, higher scores denote higher anxiety. This anxiety subscale is reliable and valid (Derogatis \& Melisaratos, 1983), and investigators have used this instrument for patients with AMI (De Jong et al., in press; Kim et al., 2000; Moser et al., 2003b). For this sample, the Cronbach's $\alpha$ reliability coefficient was .84. Normative values for healthy persons, psychiatric outpatients, and psychiatric inpatients are $.35 \pm .45,1.70 \pm 1.00$, and $1.70 \pm 1.15$, respectively.

The ALI is a 1-item, verbal, numeric rating instrument. The patient is asked to rate his or her current anxiety from 0 to 10 , with 0 indicating "no anxiety" and 10 indicating the "most anxiety ever experienced." The reported score reflects the patient's state anxiety; no further calculations are necessary. This instrument was designed to resemble the 0 to 10 pain level scale that clinicians commonly use to assess pain in patients with AMI. It is impossible to calculate Cronbach's $\alpha$ on this 1-item instrument. Given the nature of state anxiety, it is also inappropriate to measure reliability of any state anxiety instrument using test-retest reliability analysis.

\section{Procedure}

The Institutional Review Boards at the three sites approved the study. Prior to data collection, all participants gave informed, written consent. Trained research assistants with cardiovascular nursing experience explained the study to potential participants, administered the anxiety assessment instruments, and obtained the patient's sociodemographic and clinical data. 
Data were collected within 48 hours of the patient's arrival at the emergency department for symptoms of AMI. The anxiety assessments took place in the patient's cardiac care unit room. Statistical Analyses

Sociodemographic and clinical data are presented as frequencies and means \pm standard deviations. Because the anxiety data were skewed towards low scores, the nonparametric Spearman's rho test was used to examine the association between the SAI and the ALI, and the association between the BSI anxiety subscale and the ALI. A $P$-value of $<.05$ was considered statistically significant. Correlations only measure the association between two instruments. Correlations may be high even when two measurement techniques are in poor agreement (Bland \& Altman, 1986). Therefore, we also used the Bland-Altman method to assess the degree of agreement between the instruments (Bland \& Altman, 1986, 1999; Glantz, 1997). Although not endorsed by all (Streiner \& Norman, 2003), the Bland-Altman method is the preferred method for evaluating whether a new instrument provides equivalent information to an existing instrument (Bland \& Altman, 1986). In summary, this method provides an assessment of bias and precision between new and existing instruments. Bland-Altman plots are useful when comparing two measurement techniques. The bias (difference between the two measures) is plotted on the $\mathrm{y}$ axis; the mean of the two measures is plotted on the $\mathrm{x}$ axis. There is no statistical test to determine whether the amount of bias seen is acceptable; instead, clinical judgment is used to decide (Bland \& Altman, 1986, 1999). Each scale had different metrics; therefore, before conducting Bland-Altman statistical analyses, we transformed the SAI and anxiety subscale of the BSI scores to a 0 to 10 scale.

Results

Sample Characteristics 
A total of 243 patients with AMI agreed to participate in this study. Table 1 contains a summary of the sociodemographic and clinical characteristics of the sample. The mean age of the participants was $62.3 \pm 13.5$ years. Female patients accounted for nearly half $(47.3 \%)$ of the sample. Nearly all (92.6\%) patients were Caucasian and the majority (69.1\%) were married. The mean education level was $12.6 \pm 3.1$ years. The peak creatine phosphokinase-MB isoenzyme level was $110.1 \pm 139.0 \mathrm{ng} / \mathrm{mL}$.

Level of Anxiety

The mean anxiety scores for the SAI, the anxiety subscale of the BSI, and the ALI were $36.76 \pm 12.01, .56 \pm .75$, and $3.08 \pm 2.62$, respectively. For the anxiety subscale of the BSI, $40.4 \%$ of patients reported higher anxiety than the normal reference mean, while $6.4 \%$ of patients were more anxious than the normal reference mean for patients with psychiatric disorders. In this sample, $42.2 \%$ of males and $72.1 \%$ of females reported anxiety levels that surpassed normal reference SAI values. Finally, $16.5 \%$ of patients had higher SAI anxiety scores than patients with neuropsychiatric disorders.

Intercorrelations Among the Anxiety Instruments

As shown in Table 2, there was a moderate, positive correlation between the SAI and the $\operatorname{ALI}(r=.52, P<.001)$. Similarly, the anxiety subscale of the BSI and the ALI were moderately correlated $(r=.45, P<.001)$.

Agreement Between SAI and ALI Anxiety Instruments

Figure 1 shows the Bland-Altman plots of the differences between the SAI and ALI anxiety instruments against the mean of these instruments. The mean difference was $1.5 \pm 2.2$, indicating that there was a moderate degree of bias between the SAI and ALI anxiety instruments. The $95 \%$ confidence interval (CI) for the bias was 1.24 to 1.80 . The limits of 
agreement indicated poor agreement between these scales. That is, given the measure of agreement calculated, patients' ALI scores could fall between 5.9 points (CI 5.42 to 6.38) above and 2.9 points $(\mathrm{CI}-3.38$ to -2.42$)$ below their SAI scores. Figure 1 shows that although most differences fall within two standard deviations of the mean difference, the bias was more pronounced for higher anxiety scores.

Agreement Between Anxiety Subscale of the BSI and ALI Anxiety Instruments

Figure 2 shows the Bland-Altman plots of the differences between the anxiety subscale of the BSI and the ALI anxiety instrument against the mean of these instruments. The mean difference was $-1.7 \pm 2.3$, indicating that there was a bias between the anxiety subscale of the BSI and the ALI anxiety instrument. The $95 \%$ confidence interval for the bias was -1.97 to -1.38. When examining the limits of agreement, patients' ALI scores may be 3.0 points above or 6.4 points below their anxiety subscale of the BSI scores. The $95 \%$ confidence interval for the lower limit of agreement was -6.86 to -5.84 ; the $95 \%$ confidence interval for the upper limit of agreement was 2.50 to 3.51 . Figure 2 shows that the bias was more pronounced for higher anxiety scores.

Discussion

The results of this study suggest that the ALI is not a valid alternative to either the SAI or the anxiety subscale of the BSI. The ALI may be convenient for clinicians and patients because it parallels a frequently used numeric pain instrument and takes less time to complete than the SAI or the anxiety subscale of the BSI. However, although ALI scores were moderately and significantly correlated with SAI and anxiety subscale of the BSI scores, results of the BlandAltman method indicate a lack of construct validity of the single-item numeric rating scale as a measure of anxiety. 
When comparing the ALI anxiety score with the SAI anxiety score, the mean difference of $1.5 \pm 2.2$ indicates a moderate systematic bias between these methods. If the ALI and SAI scores had agreed perfectly, the mean difference would have equaled zero. As shown in Figure 1, the mean difference of 1.5 is well above zero and values are scattered above and below the mean value. Furthermore, as the anxiety scores increase, more values fall outside the $95 \%$ confidence interval, indicating increasing disagreement. Importantly, the data indicate that a patient's ALI score may differ widely from his or her SAI score. For example, an ALI score of 4.0 may be as high as 9.9 or as low as 1.1, a large range that nearly encompasses the range of possible ALI scores and thus is clinically unacceptable.

The mean difference of -1.7 reveals a moderate systematic bias between ALI anxiety and BSI anxiety subscale scores. Figure 2 shows values scattered above and below the mean with more widespread disagreement for higher anxiety scores. One cannot be confident of ALI scores, as they may fall 3.0 points above or 6.4 points below anxiety subscale of the BSI scores. This means, for example, that an ALI score of 7.0 may be as high as 10 or as low as 1.4.

Although neither the SAI nor the anxiety subscale of the BSI has been designated as the "gold standard," investigators often use these instruments to assess anxiety for patients with AMI (De Jong et al., in press; Frasure-Smith \& Lesperance, 2003; Frazier et al., 2002a; Kim et al., 2000; Moser \& Dracup, 1996; Moser et al., 2003b; O'Brien et al., 2001; Watkins, Blumenthal, \& Carney, 2002). Yet, clinicians rarely use published instruments to assess patients for anxiety. Clinicians who receive vague instructions for assessing anxiety, who are unaware of published anxiety instruments, or who conclude that existing instruments are time-consuming, burdensome to patients, inaccessible, or clinically irrelevant may invent their own anxiety assessment instrument or adapt a similar scale to measure anxiety. For example, clinicians may assume that 
the ALI is a valid anxiety measure because data have supported the validity of a similarly designed verbal 0 to 10 numeric pain instrument (Paice \& Cohen, 1997). However, results of invalidated instruments may be misleading, as illustrated by our data.

A limitation of this study is that we measured anxiety one time while the patient was in the cardiac care unit. Perhaps patients would perform better on the ALI with repeated exposure to it. In addition, we did not control for how clinicians assessed patients for pain. Although patients were pain free at the time of anxiety assessment, it is possible that some patients had difficulty distinguishing between a 0 to 10 pain instrument and a 0 to 10 anxiety instrument. Finally, to promote ease of administration, we administered the ALI using a verbal approach. The ALI did not contain printed questions or statements; therefore, patients may have differed in their conceptions of anxiety. When patients completed the SAI, they responded, for example, to statements about feeling calm, tense, nervous, content, and steady. When using a more nondescriptive instrument such as the ALI, patients potentially may confuse anxiety with other emotions such as depression, hostility, or delirium. McCormack and colleagues (1988) pointed out that it is difficult to validate visual analogue scales for broad subjective concepts such as anxiety, and that not all patient groups respond alike to a particular anxiety scale.

\section{Recommendations for Future Research}

Anxiety has been shown to adversely affect physiologic and psychologic outcomes for patients with AMI; therefore, it is essential that clinicians use a valid and reliable instrument to assess anxiety. Further research is indicated to identify the instrument(s) most acceptable to clinicians and patients. Our analysis indicated that a verbal ALI instrument yielded unsatisfactory anxiety data. Future research using a printed ALI instrument with tic marks, numbers, or simple descriptors may yield more favorable results. 
Recently, McKinley and colleagues (2003) introduced the Faces Anxiety Scale, a singleitem anxiety instrument composed of five faces. The five faces range from a neutral face to a face showing extreme anxiety. Newly published data from a sample of intensive care unit patients support the validity of the Faces Anxiety Scale (McKinley et al., 2004). However, the Faces Anxiety Scale instrument has not been specifically tested with patients with AMI. Further research is necessary to evaluate whether the Faces Anxiety Scale is suitable for patients with AMI.

\section{Conclusion}

It is well known that many patients with AMI are anxious and that anxiety contributes to unfavorable patient outcomes. Critical care clinicians have not adopted a published anxiety instrument for widespread use. Based on the construct validity data from this study, we cannot recommend that clinicians use the ALI to assess anxiety in patients with AMI. The quest continues to construct a simple and valid self-report measure of anxiety that is appropriate for critically ill patients with AMI. 


\section{References}

Benotsch, E. G., Lutgendorf, S. K., Watson, D., Fick, L. J., \& Lang, E. V. (2000). Rapid anxiety assessment in medical patients: Evidence for the validity of verbal anxiety ratings. Annals of Behavioral Medicine, 22, 199-203.

Bland, J. M., \& Altman, D. G. (1986). Statistical methods for assessing agreement between two methods of clinical measurement. Lancet, 1,307-310.

Bland, J. M., \& Altman, D. G. (1999). Measuring agreement in method comparison studies. Statistical Methods in Medical Research, 8, 135-160.

Boker, A., Brownell, L., \& Donen, N. (2002). The Amsterdam preoperative anxiety and information scale provides a simple and reliable measure of preoperative anxiety. Canadian Journal of Anaesthesia, 49, 792-798.

Bucher, L. (1999). Acute myocardial infarction. In L. Bucher \& S. Melander (Eds.), Critical Care Nursing (pp. 227-257). Philadelphia: W.B. Saunders.

Casey, P. E., Morrissey, A., \& Nolan, E. M. (1998). Ischemic heart disease. In M. R. Kinney, S. B. Dunbar, J. O. Brooks-Brunn, N. Molter \& J. M. Vitello-Cicciu (Eds.), $A A C N^{\prime} s$ Clinical Reference for Critical Care Nursing (4th ed., pp. 319-381). St. Louis: Mosby.

Crowe, J. M., Runions, J., Ebbesen, L. S., Oldridge, N. B., \& Streiner, D. L. (1996). Anxiety and depression after acute myocardial infarction. Heart \& Lung, 25, 98-107.

Cunningham, S., Del Bene, S., \& Vaughan, A. F. (2000). Myocardial ischemia and infarction. In S. L. Woods, E. S. Froelicher \& S. U. Motzer (Eds.), Cardiac Nursing (4th ed., pp. 481540). Philadelphia: Lippincott. 
De Jong, M. J., Chung, M. L., Roser, L. P., Jensen, L. A., Kelso, L. A., Dracup, K., et al. (in press). A five-country comparison of anxiety early after acute myocardial infarction. European Journal of Cardiovascular Nursing.

Denollet, J., \& Brutsaert, D. L. (1998). Personality, disease severity, and the risk of long-term cardiac events in patients with a decreased ejection fraction after myocardial infarction. Circulation, 97, 167-173.

Derogatis, L. R., \& Melisaratos, N. (1983). The Brief Symptom Inventory: An introductory report. Psychological Medicine., 13, 595-605.

Frasure-Smith, N., \& Lesperance, F. (2003). Depression and other psychological risks following myocardial infarction. Archives of General Psychiatry, 60, 627-636.

Frasure-Smith, N., Lesperance, F., \& Talajic, M. (1995). The impact of negative emotions on prognosis following myocardial infarction: Is it more than depression? Health Psychology, 14, 388-398.

Frazier, S. K., Moser, D. K., O'Brien, J. L., Garvin, B. J., An, K., \& Macko, M. (2002a). Management of anxiety after acute myocardial infarction. Heart \& Lung, 31, 411-420.

Frazier, S. K., Moser, D. K., Riegel, B., McKinley, S., Blakely, W., Kim, K. A., et al. (2002b). Critical care nurses' assessment of patients' anxiety: reliance on physiological and behavioral parameters. American Journal of Critical Care, 11, 57-64.

Glantz, S. A. (1997). Primer of biostatistics (4th ed.). New York: McGraw-Hill.

Kim, K. A., Moser, D. K., Garvin, B. J., Riegel, B. J., Doering, L. V., Jadack, R. A., et al. (2000). Differences between men and women in anxiety early after acute myocardial infarction. American Journal of Critical Care, 9, 245-253. 
Malan, S. S. (1992). Psychosocial adjustment following MI: Current views and nursing implications. Journal of Cardiovascular Nursing, 6, 57-70.

Martinez, L. G. (2004). Coronary artery disease and acute coronary syndrome. In S. M. Lewis, M. M. Heitkemper \& S. R. Dirksen (Eds.), Medical-Surgical Nursing: Assessment and Management of Clinical Problems (pp. 799-837). St. Louis: Mosby.

McCormack, H. M., Horne, D. J., \& Sheather, S. (1988). Clinical applications of visual analogue scales: A critical review. Psychological Medicine, 18, 1007-1019.

McKinley, S., Coote, K., \& Stein-Parbury, J. (2003). Development and testing of a Faces Scale for the assessment of anxiety in critically ill patients. Journal of Advanced Nursing, 41, 73-79.

McKinley, S., Stein-Parbury, J., Chehelnabi, A., \& Lovas, J. (2004). Assessment of anxiety in intensive care patients by using the Faces Anxiety Scale. American Journal of Critical Care, 13, 146-152.

Moser, D. K., Chung, M. L., McKinley, S., Riegel, B., An, K., Cherrington, C. C., et al. (2003a). Critical care nursing practice regarding patient anxiety assessment and management. Intensive and Critical Care Nursing, 19, 276-288.

Moser, D. K., \& Dracup, K. (1996). Is anxiety early after myocardial infarction associated with subsequent ischemic and arrhythmic events? Psychosomatic Medicine, 58, 395-401.

Moser, D. K., Dracup, K., McKinley, S., Yamasaki, K., Kim, C.-J., Riegel, B., et al. (2003b). An international perspective on gender differences in anxiety early after acute myocardial infarction. Psychosomatic Medicine, 65, 511-516.

O'Brien, J. L., Moser, D. K., Riegel, B., Frazier, S. K., Garvin, B. J., \& Kim, K. A. (2001). Comparison of anxiety assessments between clinicians and patients with acute 
myocardial infarction in cardiac critical care units. American Journal of Critical Care, 10,97-103.

Paice, J. A., \& Cohen, F. L. (1997). Validity of a verbally administered numeric rating scale to measure cancer pain intensity. Cancer Nursing, 20, 88-93.

Rose, S. K., Conn, V. S., \& Rodeman, B. J. (1994). Anxiety and self-care following myocardial infarction. Issues in Mental Health Nursing, 15, 433-444.

Spielberger, C. D. (1972). Anxiety as an emotional state. In C. D. Spielberger (Ed.), Anxiety: Current trends in theory and research (Vol. I, pp. 23-49). New York: Academic Press.

Spielberger, C. D., Gorsuch, R. L., Lushene, R., Vagg, P. R., \& Jacobs, G. A. (1983). Manual for the state-trait anxiety inventory. Palo Alto, CA: Consulting Psychologists.

Streiner, D. L., \& Norman, G. R. (2003). Health measurement scales: A practical guide to their development and use. New York: Oxford University Press.

Thomas, S. A., Friedmann, E., Wimbush, F., \& Schron, E. (1997). Psychological factors and survival in the cardiac arrhythmia suppression trial (CAST): A reexamination. American Journal of Critical Care, 6, 116-126.

Watkins, L. L., Blumenthal, J. A., \& Carney, R. M. (2002). Association of anxiety with reduced baroreflex cardiac control in patients after acute myocardial infarction. American Heart Journal, 143, 460-466.

Webb, M. S., \& Riggin, O. Z. (1994). A comparison of anxiety levels of female and male patients with myocardial infarction. Critical Care Nurse, 14 (1), 118-124. 


\section{Figure Legends}

FIGURE 1. Bland-Altman Plot of the Differences Against the Mean Responses for the State Anxiety Index and Anxiety Level Index

FIGURE 2. Bland-Altman Plot of the Differences Against the Mean Responses for the Brief Symptom Inventory Anxiety Subscale and Anxiety Level Index 
FIGURE 1.

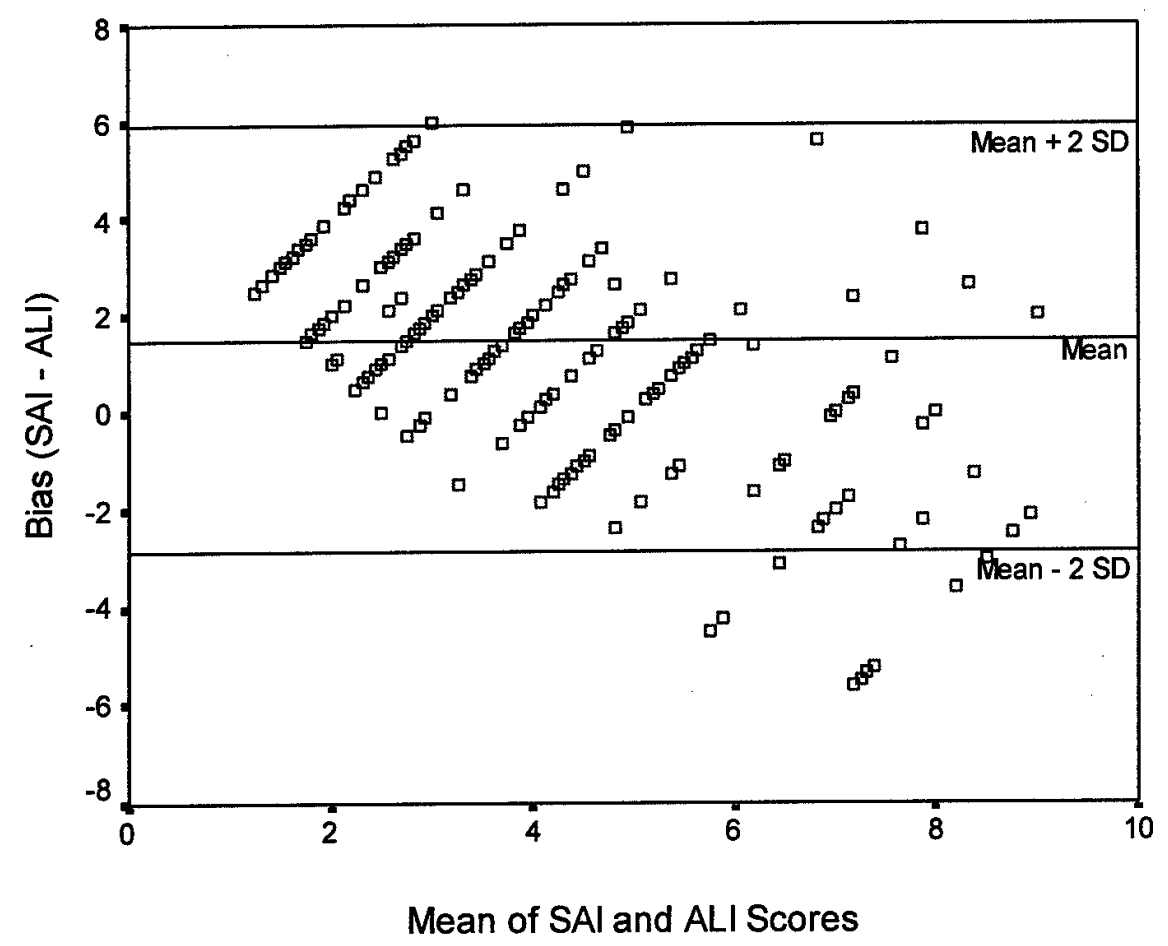

$\mathrm{SAI}=$ State Anxiety Index; ALI = Anxiety Level Index 
FIGURE 2.

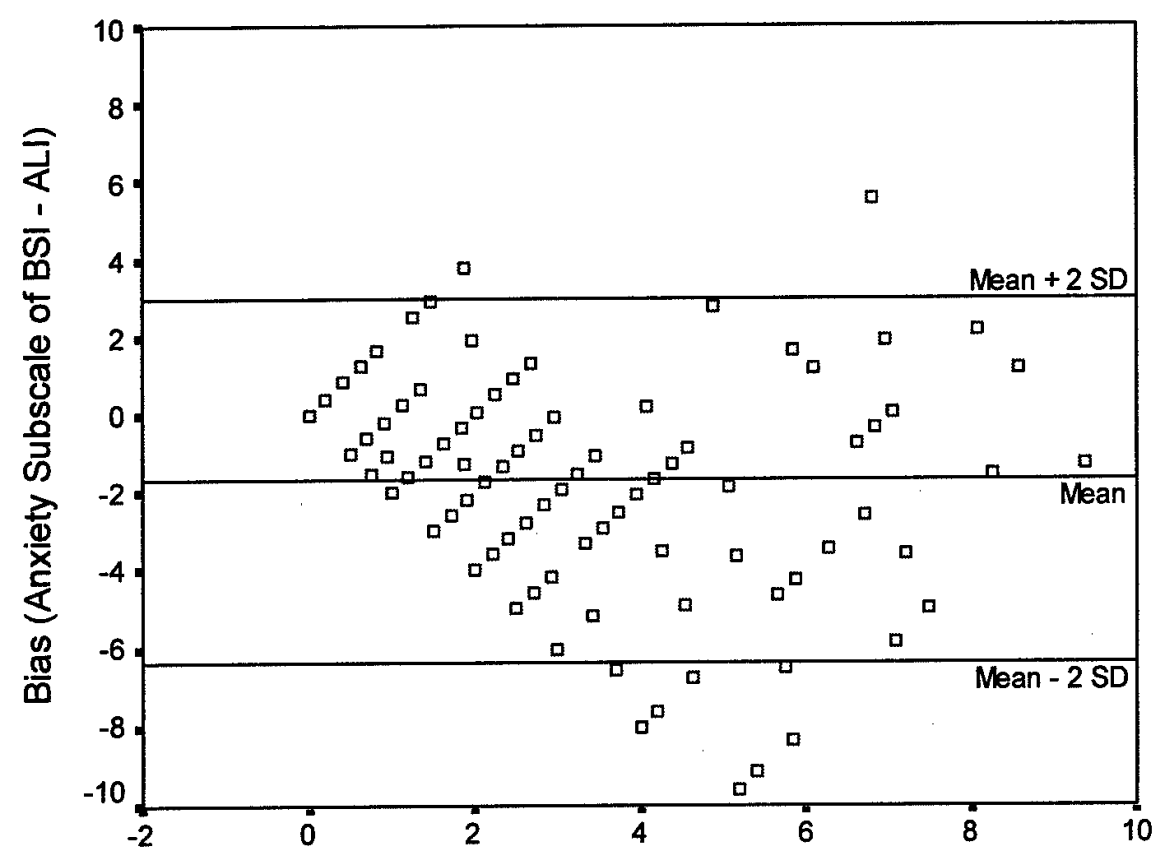

Mean BSI Anxiety Subscale and ALI Scores

BSI = Brief Symptom Inventory; ALI = Anxiety Level Index 
TABLE 1. Sample Baseline Characteristics $(N=243)$

\begin{tabular}{|c|c|c|}
\hline Characteristic & $n$ & $\%$ \\
\hline Male gender & 128 & $(52.7)$ \\
\hline \multicolumn{3}{|l|}{ Ethnicity } \\
\hline $\begin{array}{l}\text { Caucasian } \\
\text { Black } \\
\text { Middle Eastern Caucasian } \\
\text { Hispanic }\end{array}$ & $\begin{array}{r}225 \\
14 \\
2 \\
1\end{array}$ & $\begin{array}{r}(92.6) \\
(5.8) \\
(0.8) \\
(0.4)\end{array}$ \\
\hline \multicolumn{3}{|l|}{ Marital status } \\
\hline $\begin{array}{l}\text { Married } \\
\text { Widowed } \\
\text { Divorced } \\
\text { Single } \\
\text { Separated } \\
\text { Cohabitate }\end{array}$ & $\begin{array}{r}168 \\
38 \\
23 \\
11 \\
2 \\
1\end{array}$ & $\begin{array}{r}(69.1) \\
(15.6) \\
(9.5) \\
(4.5) \\
(0.8) \\
(0.4)\end{array}$ \\
\hline History of AMI & 71 & $(29.2)$ \\
\hline History of CABG & 24 & $(9.9)$ \\
\hline History of HTN & 132 & $(54.3)$ \\
\hline History of diabetes & 60 & $(24.7)$ \\
\hline Current smoker & 63 & $(25.9)$ \\
\hline \multicolumn{3}{|c|}{ Location of myocardial infarction ${ }^{\ddagger}$} \\
\hline $\begin{array}{l}\text { Inferior } \\
\text { Anterior } \\
\text { Lateral } \\
\text { Posterior } \\
\text { Apical }\end{array}$ & $\begin{array}{r}111 \\
90 \\
48 \\
35 \\
6\end{array}$ & $\begin{array}{r}(45.7) \\
(37.0) \\
(19.8) \\
(14.4) \\
(2.5)\end{array}$ \\
\hline \multicolumn{3}{|c|}{ Killip classification on admission } \\
\hline $\begin{array}{l}\text { I } \\
\text { II } \\
\text { III } \\
\text { IV }\end{array}$ & $\begin{array}{r}169 \\
56 \\
14 \\
1\end{array}$ & $\begin{array}{r}(69.5) \\
(23.0) \\
(5.8) \\
(0.4)\end{array}$ \\
\hline
\end{tabular}

Columns may not add to $100 \%$ because of missing data 
$\mathrm{AMI}=$ acute myocardial infarction $; \mathrm{CABG}=$ coronary artery bypass grafting; $\mathrm{HTN}=$ hypertension

$\ddagger$ Some patients had more than one type of myocardial infarction 
TABLE 2. Correlations between the Spielberger State Anxiety Index, the Anxiety Subscale of the Brief Symptom Inventory, and the Anxiety Level Index

\begin{tabular}{lcc}
\hline & Anxiety Level Index & $\begin{array}{c}\text { Anxiety Subscale of } \\
\text { the Brief Symptom } \\
\text { Inventory }\end{array}$ \\
\hline $\begin{array}{l}\text { Spielberger State } \\
\text { Anxiety Index }\end{array}$ & $.52^{*}$ & $.56^{*}$ \\
$\begin{array}{l}\text { Anxiety Subscale of } \\
\text { the Brief Symptom } \\
\text { Inventory }\end{array}$ & & \\
\hline
\end{tabular}

${ }^{*} P<.001$ by Spearman's rho 